\title{
Survei Pengetahuan Kader Muhammadiyah/Aisyiyah Pada Bantuan Hidup Dasar
}

\author{
Ardi Pramono', Muhammad Kurniawan ${ }^{2}$ \\ 1Bagian Anestesi dan Terapi Intensif Program Studi Profesi Dokter \\ 2Bagian Parasitologi \\ Fakultas Kedokteran dan Ilmu Kesehatan, Universitas Muhammadiyah Yogyakarta, Jalan Brawijaya, Kasihan, Bantul, Yogyakarta, \\ 55183 \\ Email: ardipramono@umy.ac.id \\ DOI: 10.18196/ppm.39.128
}

\begin{abstract}
Abstrak
Berdasarkan data dari badan kesehatan dunia WHO (World Health Organization) tahun 2012, terdapat 17,5 juta atau 31\% dari kematian di seluruh dunia yang meninggal akibat penyakit kardiovaskuler atau jantung dan pembuluh darah. Di Indonesia berdasarkan data Riskesdas tahun 2013 menunjukkan bahwa prevalensi tertinggi penyakit kardiovaskuler adalah penyakit jantung koroner (PJK) yang dapat mengalami henti jantung mendadak. Henti jantung tidak jarang terjadi di tengah masyarakat dan perlu mendapat pertolongan segera sehingga kemungkinan berhasil lebih besar. Kader Muhammadiyah dan Aisyiyah sebagai ujung tombak penggerak kesadaran hidup sehat di masyarakat perlu mengetahui dan memberi contoh tindakan pertolongan henti jantung pada masyarakat. Pengabdian masyarakat di era pandemi Covid-19 ini bertujuan untuk membentuk masyarakat kader Muhammadiyah dan Aisyiyah yang mampu mengenali dan melakukan pertolongan henti jantung di masyarakat sebelum dibawa ke fasilitas kesehatan. Kegiatan diawali dengan survei secara online menggunakan Google Form tentang pengetahuan bantuan hidup dasar. Hasil survei menunjukkan bahwa 96,1\% kader setuju diadakan pelatihan dan penyuluhan secara offline maupun online karena hanya sekitar 3,6\% yang tahu cara menangani korban henti jantung.
\end{abstract}

Kata Kunci: bantuan hidup dasar, kader Muhammadiyah

Pendahuluan

Perkembangan ilmu kedokteran yang semakin maju berakibat pada meningkatnya populasi orang dengan umur di atas 65 tahun atau geriatri. Menurut Badan Kesehatan Dunia (WHO), pada tahun 2012 terdapat 17,5 juta atau 31\% pasien meninggal karena penyakit kardiovaskuler jantung dan pembuluh darah ("WHO: Cardiovascular Diseases [CVDs]," 201AD). Di Indonesia terdapat prevalensi tinggi penyakit kardiovaskuler dan kejadiannya terus meningkat (Boedhi-Darmojo, 1993) (Adisasmito et al., 2020). Meskipun angka kejadiannya makin meningkat, hal ini tidak diimbangi dengan perawatan yang memadai dan belum merata di setiap daerah di Indonesia (Maharani et al., 2019; Maharani and Tampubolon, 2014). Terdapat faktor risiko penyakit yang berbeda antara penduduk perkotaan yang didominasi penyakit diabetes, kegemukan, dan hipertensi, dibandingkan penduduk pedesaan yang didominasi ketidakaktifan fisik dan merokok (Adisasmito et al., 2020).

Penyakit kardiovaskuler seperti penyakit jantung koroner dapat mengalami henti jantung mendadak. Penyakit jantung koroner memiliki faktor risiko seperti kadar trigliserida, penyakit diabetes, hipertensi, dan obesitas yang dapat dimodifikasi (Ghasemzadeh et al., 2018). Pertolongan henti jantung mendadak harus dilakukan secara tepat dan cepat karena semakin cepat diberikan pertolongan, harapan hidup lebih baik (Ghasemzadeh et al., 2018; Hara et al., 2015).

Pengabdian masyarakat ini bertujuan melatih kader Muhammadiyah dan Aisyiyah agar mengetahui gejala henti jantung dan napas serta cara pertolongannya. Target pelatihan adalah membentuk kelompok kesehatan masyarakat yang dapat memberikan pelatihan serupa dengan dampingan dari tim UMY bagi masyarakat lain yang memerlukan. Skema sosialisasi berupa kuliah/penyuluhan kepada kader Muhammadiyah dan Aisyiyah di Desa Moyudan, Sleman. Agar hasil lebih luas dan karena kondisi pandemi, dilakukan juga pelatihan secara online menggunakan video yang diunggah di youtube. Tahap awal pengabdian berupa survei 
pengetahuan awal tentang diagnosis dan pertolongan bantuan hidup dasar pada korban henti jantung.

\section{Metode Pelaksanaan}

Pengabdian masyarakat ini dilakukan dengan cara survey cross sectional kepada kader Muhammadiyah dan Aisyiyah menggunakan Google Form yang disebarkan secara daring. Survei menanyakan jenis kelamin dan umur, pengetahuan tentang tanda-tanda henti napas dan jantung, serta pengetahuan cara pertolongannya.

\section{Hasil dan Pembahasan}

Dari survei melalui Google Form, didapat 56 responden yang terdiri atas laki-laki 39 orang dan perempuan 16 orang (Diagram 1), dengan rerata umur laki-laki 43,4 tahun dan perempuan 45,5 tahun (Diagram 2). Pada petanyaan tentang apa yang dilakukan jika menemukan korban pingsan, hanya 3,6\% yang menjawab melakukan pijat jantung, lainnya menjawab panggil bantuan $(21,4 \%)$, memberi bau-bauan yang merangsang $(32,1 \%)$, dan $42,9 \%$ menolong sebisanya. Tidak ada responden yang meninggalkan tempat kejadian (Diagram 3). Terdapat 46,4\% responden yang menjawab benar cara mengetahui bahwa korban mengalami henti jantung, sisanya menjawab pingsan (37,5\%), dan 16,1\% menjawab tidak tahu (Diagram 4). Sebanyak 69,6\% responden mengetahui cara memeriksa denyut nadi (Diagram 5) dan 69,1\% tahu cara mengetahui korban bernapas atau tidak (Diagram 6). Responden yang menginginkan ada pelatihan resusitasi jantung paru (RJP) sebanyak 96,1\% (Diagram 7).

\section{Jumlah Responden}

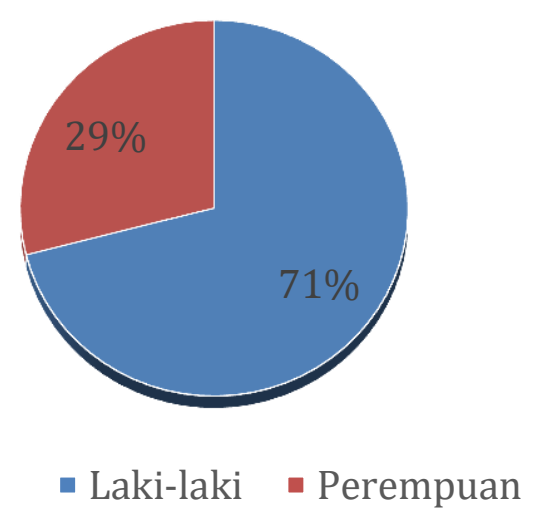

Diagram 1. Jenis Kelamin Responden 


\section{Rerata Umur}

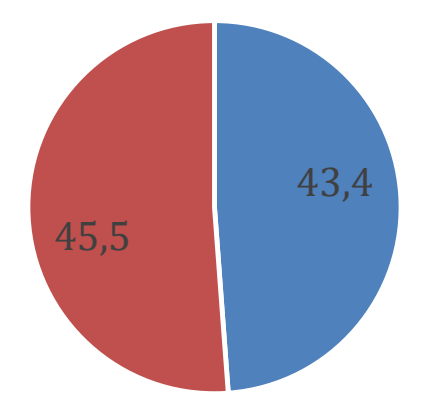

\section{- Laki-laki - Perempuan}

Diagram 2. Rerata Umur Responden

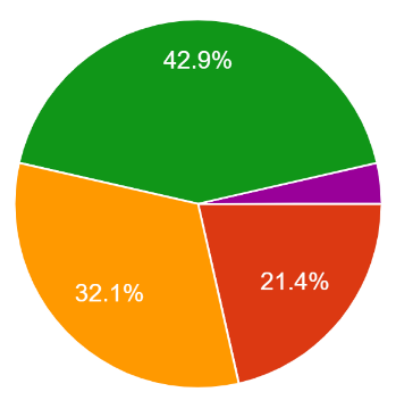

a. Segera meninggalkan tempat kejadian karena tidak tahu harus berbuat apa

b. Berteriak memanggil bantuan

c. Ambil bau-bauan agar merangsang kesadaran

d. Menolong sebisanya

e. Melakukan pijat jantung

Diagram 3. Apa yang Dilakukan Saat Menemukan Korban Pingsan

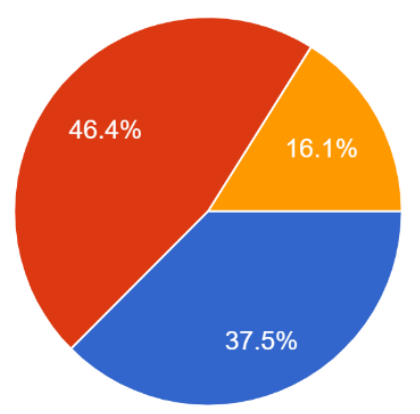

a. Jatuh pingsan

b. Tidak teraba denyut jantung

c. Tidak tahu

Diagram 4. Pengetahuan tentang Tanda-tanda Henti Jantung 


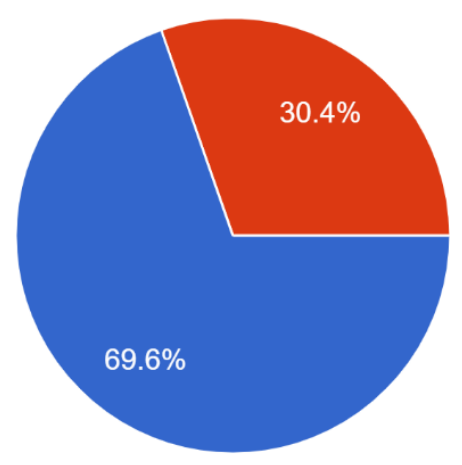

Diagram 5. Pengetahuan Responden tentang Cara Memeriksa Denyut Nadi

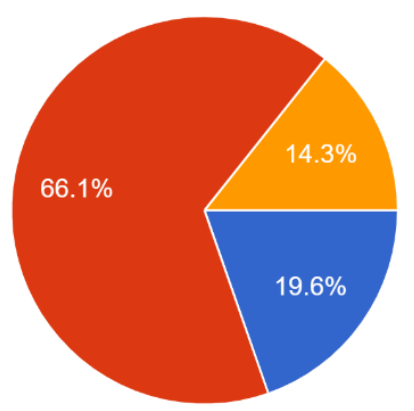

a. Jatuh pingsan

b. Tidak terlihat dada kembang kempis

c. Tidak tahu

Diagram 6. Pengetahuan Responden tentang Tanda Henti Napas

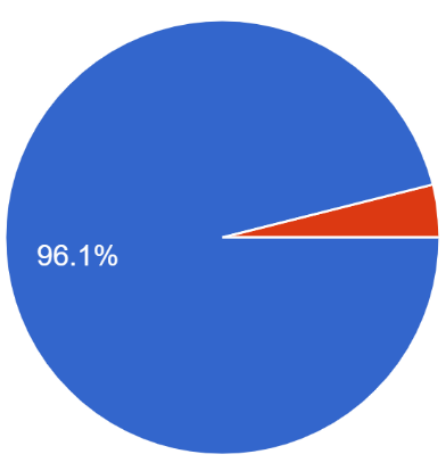

Ya

Tidak

Diagram 7. Keinginan Responden untuk Diadakan Pelatihan Pertolongan RJP

Lebih dari 350.000 orang per tahun mengalami henti jantung dan hanya $12 \%$ yang berhasil diselamatkan ("CPR-Proficient High School Graduates Are the Next Generation of Lifesaving Bystanders," 2017). Penyakit kardiovaskuler di Indonesia menempati urutan ke-9 dari 22 penyakit penyebab kematian dan dapat menyebabkan kualitas kesehatan yang buruk (Komalasari et al., 2019). Pertolongan henti jantung harus dilakukan sedini mungkin sehingga harapan hidup meningkat. Banyak pasien henti jantung terjadi di luar rumah sakit dan harus segera dilakukan pertolongan. Penelitian Hara (2015) pada korban henti jantung di luar rumah sakit menyebutkan bahwa semakin cepat diberikan pertolongan maka hasil yang diperoleh akan semakin baik jika dibandingkan dengan pertolongan yang terlambat. Hasil tersebut terlepas dari jenis irama jantung saat ditemukan pertama kali pada korban (Hara et al., 2015). 
Pada penelitian ini diperoleh 56 responden yang terdiri atas $71 \%$ laki-laki dan $29 \%$ perempuan dengan rerata umur 44 tahun. Lebih dari $60 \%$ responden mengetahui tanda-tanda henti jantung dan henti napas, tetapi hanya 3,6\% responden melakukan pertolongan penyelamatan henti jantung yang benar berupa pijat jantung luar. Responden setuju dilakukan pelatihan pertolongan henti jantung $(96,1 \%)$. Sebuah penelitian survei di Brazil baru-baru ini menyatakan bahwa pada sepertiga responden yang merupakan masyarakat sipil tidak dapat mengidentifikasi faktor risiko penyakit kardiovaskuler dan seperempat responden tidak dapat menunjukkan gejala infark miokard. Secara umum, pada survei di Brazil, hanya sedikit responden yang mengetahui tentang bantuan hidup dasar (RJP) dan diperlukan pelatihan yang terus-menerus.

Henti jantung merupakan tanda kegawatan yang harus segera ditolong dan $80 \%$ terjadi di rumah atau fasilitas tempat tinggal lain di luar rumah sakit. Penyebab henti jantung mendadak biasanya karena gangguan listrik jantung yang dapat berupa PEA sampai asistol (Patil et al., 2015) yang kemungkinan berhubungan dengan metabolisme ion Ca (Liao et al., 1996). Patil (2015) menyatakan bahwa saat ini pertolongan dini dengan defibrilasi dan RJP masih merupakan pertolongan terbaik selain memperbaiki fungsi mitokondria dan menghindari cedera reperfusi (Patil et al., 2015).

Latar belakang budaya masyarakat sangat berpengaruh terhadap keputusan pertolongan tindakan RJP. Pada penelitian ini, tidak ada masyarakat yang meninggalkan korban, tetapi akan berusaha menolong walaupun tidak tahu bagaimana menolong dengan benar (Diagram 3). Orang beragama lebih cenderung melakukan usaha perbaikan hidup pasien walaupun sia-sia (Bulow et al., 2012). Dokter Meksiko cenderung mengabaikan pasien yang memerlukan RJP dibandingkan dengan di Indonesia dan Israel (Ozer et al., 2019).

Meskipun penelitian ini hanya mengandalkan pengambilan data secara survei pada masyarakat tertentu (kader Muhammadiyah/Aisyiyah), tetapi temuan hasil survei dapat memberikan sedikit gambaran untuk pengembangan pelatihan RJP pada masyarakat umum. Pelatihan yang terus-menerus dapat memberikan pengetahuan tentang cara melakukan RJP yang berkualitas sehingga angka keberlangsungan hidup korban henti jantung meningkat (Cheng Adam et al., 2018).

\section{Simpulan}

Berdasarkan survei tersebut dapat disimpulkan bahwa pengetahuan kader Muhammadiyah/Aisyiyah tentang henti jantung masih belum seragam dan hanya sedikit yang mengetahui cara pertolongannya.

\section{Ucapan Terima Kasih}

Peneliti mengucapkan terima kasih kepada LP3M UMY atas bantuan dana untuk mengadakan pengabdian masyarakat dan survei ini.

\section{Daftar Pustaka}

Adisasmito, W., Amir, V., Atin, A., Megraini, A., Kusuma, D., (2020). Geographic and Socioeconomic Disparity in Cardiovascular Risk Faktors in Indonesia: Analysis of the Basic Health Research 2018. BMC Public Health 20, 1004. https://doi.org/10.1186/s12889-020-09099-1.

Boedhi-Darmojo, R. (1993). The Pattern of Cardiovascular Disease in Indonesia. World Health Stat. Q. Rapp. Trimest. Stat. Sanit. Mond. 46, 119-124. 
Bülow, H.H., Sprung, C.L., Baras, M., Carmel, S., Svantesson, M., Benbenishty, J., Maia, P.A., Beishuizen, A., Cohen, S., Nalos, D. (2012). Are Religion and Religiosity Important to End-of-Life Decisions and Patient Autonomy in the ICU? The Ethicatt Study. Intensive Care Med. 38, 1126-1133. https://doi.org/10.1007/s00134-012-2554-8.

Cheng Adam, Nadkarni Vinay M., Mancini Mary Beth, Hunt Elizabeth A., Sinz Elizabeth H., Merchant Raina M., Donoghue Aaron, Duff Jonathan P., Eppich Walter, Auerbach Marc, Bigham Blair L., Blewer Audrey L., Chan Paul S., Bhanji Farhan, null null. (2018). Resuscitation Education Science: Educational Strategies to Improve Outcomes from Cardiac Arrest: A Scientific Statement from the American Heart Association. Circulation 138, e82-e122. https://doi.org/10.1161/CIR.0000000000000583.

CPR-Proficient High School Graduates Are the Next Generation of Lifesaving Bystanders [WWW Document]. (2017). JEMS. URL https://www.jems.com/2017/12/01/cprproficient-high-school-graduates-are-the-next-generation-of-lifesaving-bystanders/ (accessed 9.18.20).

Ghasemzadeh, G., Soodmand, M., Moghadamnia, M.T. (2018). The Cardiac Risk Faktors of Coronary Artery Disease and Its Relationship with Cardiopulmonary Resuscitation: A retrospective Study. Egypt. Heart J. 70, 389-392. https://doi.org/10.1016/j.ehj.2018.07.005.

Hara, M., Hayashi, K., Hikoso, S., Sakata, Y., Kitamura, T. (2015). Different Impacts of Time From Collapse to First Cardiopulmonary Resuscitation on Outcomes After Witnessed Out-of-Hospital Cardiac Arrest in Adults. Circ. Cardiovasc. Qual. Outcomes 8, 277-284. https://doi.org/10.1161/CIRCOUTCOMES.115.001864.

Komalasari, R., Nurjanah, null, Yoche, M.M. (2019). Quality of Life of People with Cardiovascular Disease: A Descriptive Study. AsianPacific Isl. Nurs. J. 4, 92-96. https://doi.org/10.31372/20190402.1045.

Liao, R., Nascimben, L., Friedrich, J., Gwathmey, J.K., Ingwall, J.S. (1996). Decreased Energy Reserve in An Animal Model of Dilated Cardiomyopathy. Relationship to Contractile Performance. Circ. Res. 78, 893-902. https://doi.org/10.1161/01.res.78.5.893.

Maharani, A., Sujarwoto, Praveen, D., Oceandy, D., Tampubolon, G., Patel, A. (2019). Cardiovascular Disease Risk Faktor Prevalence and Estimated 10-Year Cardiovascular Risk Scores in Indonesia: The SMARThealth Extend Study. PLOS ONE 14, e0215219. https://doi.org/10.1371/journal.pone.0215219.

Maharani, A., Tampubolon, G. (2014). Unmet Needs for Cardiovascular Care in Indonesia. PloS One 9, e105831. https://doi.org/10.1371/journal.pone.0105831.

Ozer, J., Alon, G., Leykin, D., Varon, J., Aharonson-Daniel, L., Einav, S. (2019). Culture and Personal Influences on Cardiopulmonary Resuscitation-Results of International Survey. BMC Med. Ethics 20. https://doi.org/10.1186/s12910-019-0439-x.

Patil, K., Halperin, H.R., Becker, L.B. (2015). Cardiac Arrest: Resuscitation and Reperfusion. Circ. Res. 116, 2041-2049. https://doi.org/10.1161/CIRCRESAHA.116.304495.

WHO: Cardiovascular Diseases (CVDs) [WWW Document], 201AD. WHO. URL http://www.who.int/cardiovascular_diseases/en/ (accessed 5.9.18). 